NOTICE: this is the author's version of a work that was accepted for publication in Applied Energy. Changes resulting from the publishing process, such as peer review, editing, corrections, structural formatting, and other quality control mechanisms may not be reflected in this document. Changes may have been made to this work since it was submitted for publication. A definitive version was subsequently published in Applied Energy, Vol. 96, August 2012, DOI: 10.1016/j.apenergy.2012.02.069 


\title{
Technological progress and the availability of European oil and gas resources
}

\author{
Roberto F. Aguilera ${ }^{a}$, Ronald D. Ripple ${ }^{b}$
}

\begin{abstract}
This paper estimates supply cost curves for conventional oil and gas in Europe. Oil and gas volumes are distributed across five categories that are based on production costs. The resulting supply figures are intended to be long term representations of how quantities vary with production costs. Both economic and physical measures are used since each provides practical information with respect to the concerns some energy commentators have expressed about oil and gas scarcity in the near future. Supply cost curves incorporating the effect of annual technological advancement (i.e. productivity gains) on production costs to the year 2030 are also estimated. On the quantity side, the curves include volumes from geological provinces not previously assessed. Results indicate that conventional oil and gas in Europe is abundant and can likely be produced at costs below current and projected market oil and gas prices.
\end{abstract}

Keywords: Technological progress; Availability; Conventional oil and gas; Europe

\section{Introduction}

Oil and gas resources have provided much of the world's energy in the twentieth century and are expected to be an important part of the energy mix well into the twenty-first century [1].

Currently, conventional oil and gas provides approximately $65 \%$ of primary energy consumption in Europe [2]. However, energy security in the region remains a concern. The concern is reinforced due to Europe's dependence on oil and gas from other regions. In addition, many commentators fear domestic oil and gas resource depletion will produce significant supply

\footnotetext{
${ }^{a}$ Corresponding Author. Centre for Research in Energy and Minerals Economics (CREME), Curtin Business School, Curtin University, GPO Box 1987, Perth 6845, Australia, Phone: 618-9266-9137, Email: r.aguilera@curtin.edu.au

b CREME, Curtin Business School, Curtin University, GPO Box 1987, Perth 6845, Australia, Phone: 618-92663935, Email: r.ripple@ curtin.edu.au
} 
scarcities in the short term, i.e., well before 2020. Thus, the purpose of this analysis is to address

4 Continued demand for oil- and gas-based energy services throughout the twenty-first century is

5 expected to induce technological change that could lower future production cost levels. On the the subject by estimating conventional oil and gas supply cost curves for the region.

other hand, environmental considerations could adversely affect oil and gas production costs, especially if unconventional resources are considered. Production of these resources typically have larger environmental impacts, including increased greenhouse gases emitted during the extraction and upgrading processes. Emissions penalties could change the shapes of the supply curves, as unconventional oil and gas would become relatively more expensive. The implementation of carbon capture and storage (CCS) at extraction sites could also increase cost, though presumably the cost would be lower than that resulting from the imposition of emissions penalties.

Meanwhile, enhanced oil and gas recovery based on $\mathrm{CO} 2$ injection would be potentially less expensive due to emissions offsets based on sequestered $\mathrm{CO} 2$.
15

From an economic point of view, relative prices will determine the dominance of oil and natural gas versus other fuels [3]. To give an example, a significant tax on carbon would increase the relative price of coal versus gas. This would lead to investment and technological advancement across the gas industry and thus induce substitution from coal to gas by decreasing the relative price of gas.

The approach for developing the conventional supply cost curves in this study is based on [4] and begins by using European oil (including natural gas liquids - NGL) and gas volumes estimated by 
the Variable Shape Distribution (VSD) model [5]. The oil and gas volumes are distributed into several classes based on resource quality. Every class is then assigned lower and upper bounds of production costs, resulting in supply cost curves. For both oil and gas, two curves are developed one is based on current technology and the other on technology performance assumed for 2030.

\section{Paradigm Choice}

7 There are two common paradigms for assessing non-renewable resources: the fixed stock versus opportunity cost paradigms. The former observes that the earth is finite; therefore, the supply of any commodity, such as oil or gas, must also be finite. Demand, on the other hand, is variable.

10 Consequently, it is only a matter of time before demand consumes all of the fixed stock. Although

11 the fixed stock paradigm seems logical, economists often argue that the methodology is less useful

12 than the opportunity cost paradigm [6]. The latter uses measures — such as prices, production costs, and the value of reserves in the ground — of what society has to give up to produce another unit in order to assess the effects of depletion and long run trends in availability. If the real price of oil rises over the long run, for instance, this would imply the oil is becoming more scarce.

In spite of the appropriateness of the opportunity cost paradigm, the fixed stock paradigm may be useful when assessing oil and gas resources in particular. The reason is that these may be the only major commodities where commentators are predicting shortages in the near term. Therefore, if reasonable estimates of oil and gas volumes available at some specified price level appear

21 sufficient to cover reasonable estimates of future demand, this provides practical information with respect to the concerns some have expressed. 
1 In this paper we use both economic and physical measures to assess the availability of oil and gas resources in Europe. First, we distribute estimates of the stock of available supply across various

3 production cost categories. We also introduce a time dimension into the supply curve estimation

4 by assessing the role of technological change to the year 2030. In particular, by incorporating the

5 effects of productivity gains on production costs over time we are also utilizing the opportunity

6 cost paradigm.

The resulting supply cost curves can be considered long term availability curves, or approximate cumulative supply curves. There are some important differences between that traditional supply curve and the cumulative supply curve. The latter, which was first proposed by [7], shows how

11 the total or cumulative supply of oil and gas varies over all time with price (see Figure 1). It

12 differs from the traditional supply curve, which shows the quantity of a resource offered to the

13 market at various prices during a specific time period, such as a month or year (see Figure 2). In

14 addition, the supply figures provided by the cumulative supply curve are stock variables, unlike

15 the traditional supply curve where they are flow variables that can continue from one period to the 16 next.

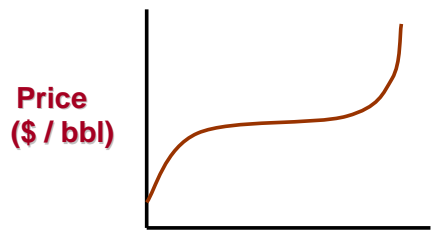

Cumulative

Quantity

(bbl)

22 Fig. 1. Cumulative supply curve representing stocks for all time. 
7

列

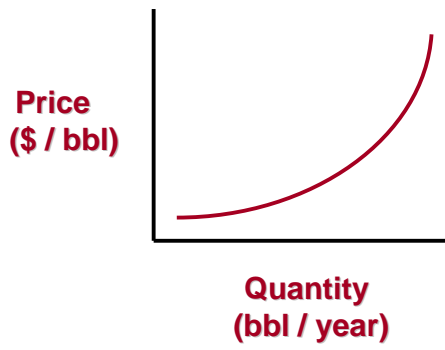

Fig. 2. Traditional supply curve representing a specified time period, such as a month or year.

\section{VSD Model}

Oil and gas endowment volumes, which are inputs into the supply cost curves, are estimated with a previously defined Variable Shape Distribution (VSD) model [8]. According to the United States Geological Survey (USGS) World Petroleum Assessment [9], endowment refers to the sum of known volumes (cumulative production plus remaining reserves) and undiscovered volumes. The VSD, a statistical method known as size distribution analysis, calculates the endowment volumes in European provinces that have not previously been assessed. ${ }^{1}$ This type of analysis has historically been successful in complementing geological techniques used to estimate resources in previously unassessed areas [10]. In this study, the VSD model is only briefly described as the focus is on supply cost curve estimation.

Traditionally, all the methods used to forecast oil and gas volumes have been "based on an assumed form of the size-frequency distribution of the natural population of oil and gas

\footnotetext{
${ }^{1}$ As defined by [9, p. GL-4], a petroleum province is an "area having characteristic dimensions of perhaps hundreds to thousands of squared kilometers encompassing a natural geologic entity (e.g. sedimentary basin, thrust belt, delta) or some combination of contiguous geologic entities."

The study adopted a 30-year time horizon and so ignored those provinces that were not expected to be producing oil and gas within that period. According to [9, p. AR-3], the areas assessed were "those judged to be significant on a world scale in terms of known petroleum volumes, geologic potential for new petroleum discoveries, and political or societal importance."
} 
accumulations" [10]. The lognormal and Pareto (fractal) distributions are common size distribution models used to estimate volumes of unassessed areas. Some researchers believe that the distribution of nature's resources follow lognormal distributions [11]. Other researchers claim the lognormal distribution provides overly pessimistic results [12]. More recently, it has generally been acknowledged that the Pareto distribution tends to overestimate oil and gas resources, while the lognormal distribution tends to underestimate them.

The VSD is unique in that we first observe the curvature (on a log-log plot) given by the size and number of assessed provinces by [9]. We then develop the VSD model which allows the data to determine the specified relationship between the size and number of provinces. In [8], the model

11 has been used successfully, typically with coefficients of determination $\left(\mathrm{R}^{2}\right)$ equal to or greater

12 than 0.98 , to match available global data for conventional oil, gas, and natural gas liquids. The

13 close matches allow us to extend the model out of sample to include previously unassessed

14 provinces in the analysis. As is common in size distribution models, the original sample contains

15 the largest provinces, meaning that most of those previously unassessed will be smaller in terms of 16 volumes [13]. For a detailed mathematical description of the VSD, refer to [8].

18 Recently, the VSD model was validated in [5] by comparing VSD-calculated and actual European endowment volumes published by [9]. Examples of the results, for conventional oil (including

20 NGL) and gas, are presented in Figure 3. The plots show the number (rank) versus size of oil and 21 gas endowment provinces estimated by [5] and [9]. 
to 12 geological provinces assessed by [9]. This endowment, estimated at approximately 102

billion barrel of oil equivalent (BBOE), compares well with the $101 \mathrm{BBOE}$ calculated by the VSD model. The coefficient of determination $\left(\mathrm{R}^{2}\right)$ is equal to 0.99 . Note that these volumes do not include heavy oil, oil sands, oil shale, and offshore provinces with water depths greater than 2000 meters in some cases and 4000 meters in others. ${ }^{2}$ The VSD model was then used to estimate the conventional oil volumes of the 62 provinces recognized by the USGS to exist in Europe, out of which 50 had not been evaluated previously. The black solid curve, generated by the VSD model, corresponds to 62 provinces and gives an oil endowment of $146 \mathrm{BBOE}$. If the effect of reserve growth of $43 \%$ is taken into account, this volume increases to $208 \mathrm{BBOE}$ and is represented by the dashed curve. For more on reserve growth and its application, refer to [5] and [14]. The lower

11 graph in Figure 3 shows results for conventional gas in Europe. The total gas endowment in all 62

12 provinces, including reserve growth, is approximately 2188 trillion cubic feet (TCF).

14 Probability distributions are used in [9] to account for the uncertainty in estimating oil and gas volumes. Fractiles (F95, F50, F5, and the mean) are shown graphically in the study for undiscovered oil and gas. For instance, the value of F50 would imply there is a $50 \%$ chance of the existence of at least the volume estimated. Inevitably, the uncertainties present in [9] extend to the VSD model.

20 The predictive power of the VSD model has been partly validated by a good fit of the size 21 distribution of previously assessed European provinces. The fit is supported by high coefficients

\footnotetext{
${ }^{2}$ Originally, [9] delineated offshore province areas to water depths of 2000 meters but then extended the analysis to several 4000 meter areas due to rapidly developing drilling and production technology.
} 
1 of determination and estimated VSD volumes that are close to those published by the USGS.

2 Nevertheless, a comparison of the VSD curves with the USGS data points shows there are some

3 differences at certain levels. The differences are accounted for in Figure 3 by plotting $20 \%$

4 horizontal error bars. As can be seen, the $20 \%$ error bars exceed the difference between the

$5 \quad$ USGS and VSD calculated points in almost all cases.

6 

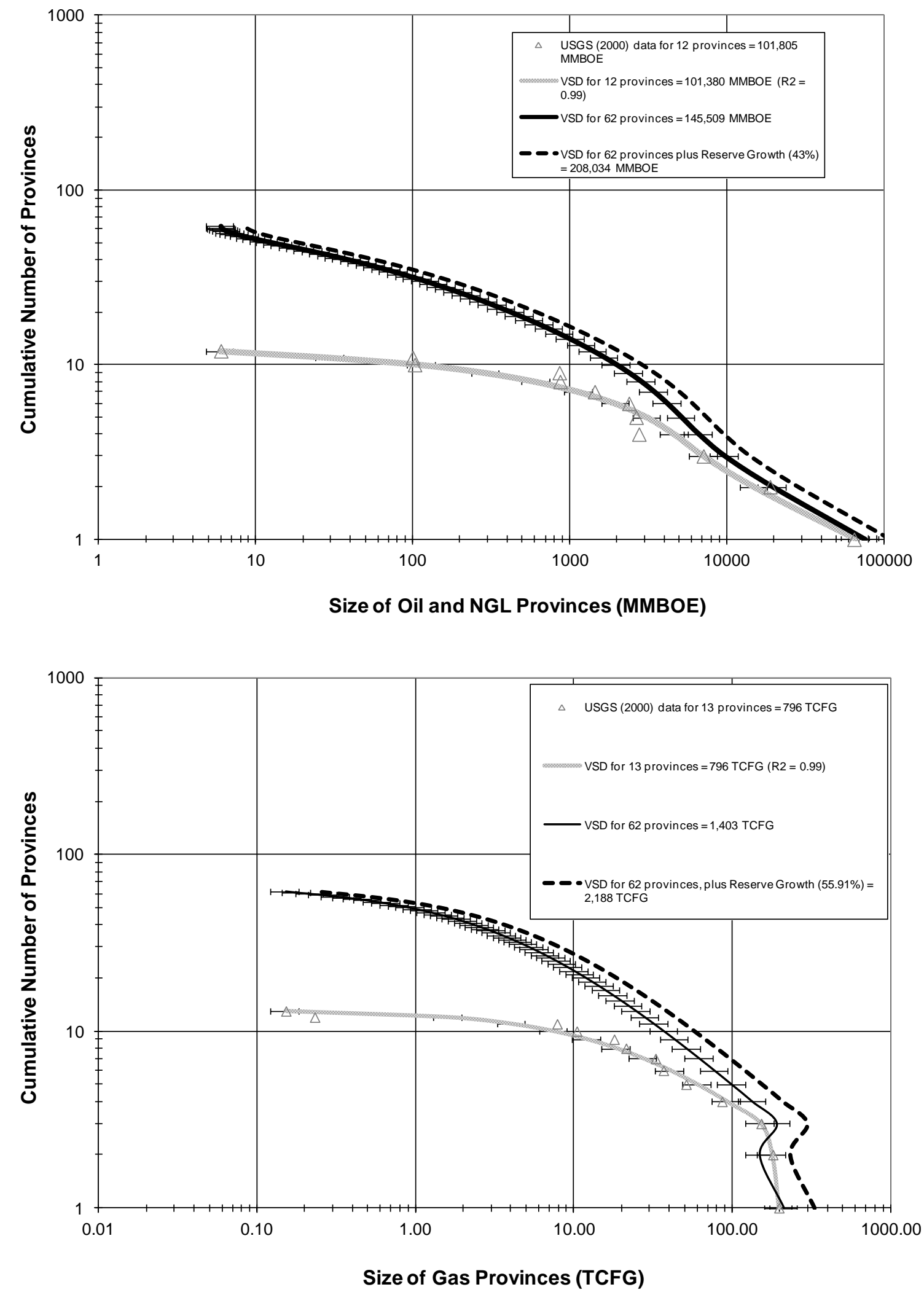

Fig. 3. European oil and gas endowments as estimated by [5] and [9]. 


\section{Oil and Gas Production Costs}

Detailed oil and gas production costs are difficult to find. Data collected from conventional oil and gas fields in Europe show a wide spread of operating and capital costs [15]. In 2009, production costs for conventional oil ranged from 3.00 to 35.00 USD per barrel of oil equivalent (BOE), with the majority being around $15 \mathrm{USD} / \mathrm{BOE}$. The conventional gas production costs ranged from 0.50 to 3.75 USD per thousand cubic feet (MCF), with the majority costing around 0.90USD/MCF. The cost figures include capital and operating costs, including a rate of return on invested capital, but do not include taxes and royalties.

Some of the cost estimates refer to relatively shallow and favourable production conditions, while deep offshore production, for instance, can be significantly higher. Cost of oil and gas production is influenced by factors such as geological conditions, depth of accumulations, regulatory environments, and project lengths [16]. Offshore capital cost increases at greater depths are mainly due to the higher cost of platform drilling, the cost of new technology to cope with depressurization of reservoirs, and the cost of pipeline transportation. Nevertheless, considerable cost savings have been achieved over the past decades on account of improved operating methods.

Longer term projections of oil and gas production costs should account for the cost reducing effects of improved technology versus the cost increasing effects of depletion. As oil and gas fields at shallow depths will likely be exploited first (assuming suitable market and regulatory conditions), there will be a gradual shift towards deeper drilling, including offshore, as well as a shift towards unconventional sources of oil and gas. This will require increased investment costs 
1 for new wells and higher operating expenditures due to additional costs for enhanced recovery. In

2 the absence of advanced innovation, these factors are likely to drive up long run production costs.

3 However, though the past is not always an indication of the future, history would suggest that

4 producers may develop the technologies needed to offset the cost-increasing effects of deeper and

5 more remote oil and gas resources.

\section{5. Supply Cost Curves}

8 Although various organizations publish estimates of reserves and resources, it is challenging to

9 categorize these definitions under a consistent classification system. The respective organizations

10 tend to report their quantities using different terms, concepts, and boundaries. Attempts to create

11 universal resource classification systems have been undertaken by [17] and [18]. In the present

12 study, oil and gas volumes are distinguished on the basis of five production cost categories.

14 The first category (CI) represents favourable production conditions such as shallow reservoirs

15 with high quality oil. The standard definition of Proved Reserves (P90; 1P), for instance, falls

16 under CI. This category often serves as a public policy tool for many economic, political,

17 technical, and environmental considerations. Countries often utilize proved reserves to gain

18 leverage in foreign policy, to design economic plans, and to form regulatory, market and climate

19 policies. The reason is that the proved reserve definition represents quantities that are recoverable

20 under existing prices and technologies. Its use for long term investment decisions or policy

21 analyses is thus restricted. 
1 The second category (CII) represents quantities that may be currently undiscovered but have a reasonable probability of being found. Probable Reserves (P50; 2P) belong to CII. In time, these volumes will presumably come online as exploration and production efforts expand. As CI oil and gas is exhausted, CII will replace them and move into the CI category themselves.

Quantities that fall under the third category (CIII) are of a more speculative nature in terms of

7 geological information and economic feasibility. Possible Reserves (P10; 3P) fall under CIII. Over the medium to long term, as the CI and CII categories begin to dwindle, market and technological conditions should shift the CIII volumes into the CII and CI categories.

11 Categories CI to CIII represent conventional oil and gas volumes that can be delineated with

12 current geological techniques. The main characteristic of these categories is the uncertainty

13 associated with their eventual discovery. The fourth and fifth categories encompass increasing

14 uncertainty with respect to economic, geological, technical, and environmental factors.

16 The possibilities of enhanced oil and gas recovery through tertiary production methods is

17 classified as CIV, however, may also apply to CI - CIII. Additions to reserves due to increased

18 recovery factors from advanced technologies (e.g. steam injection, the use of solvents, chemical

19 methods, CCS) are included in the CIV category.

21 Oil and gas located in deep offshore reservoirs falls under the fifth category (CV). These

22 quantities cannot usually be produced with traditional methods because of technical and economic

23 limitations. Some assessments may even consider CV quantities as "unconventional" due to the 
novelty of deep sea drilling, even though the hydrocarbon itself is "conventional" by geological definitions.

Supply cost curves are a function of remaining oil and gas volumes, production costs, and technological change. Table 1 shows the current oil production costs per BOE in 2009 USD [15], the assumed annual rates of technological improvement per production cost category (based on [4]), and the projected production costs for 2030. There are five assumed cost categories with a lower and upper bound for each category. The assumed rates of technological improvement, ranging from $0.50 \%$ to $1.50 \%$ per year, reflect the observed fact that advancement is greater under favourable production conditions. ${ }^{3}$ Applying an assumed rate is based on recent approaches to modeling technological change that capture the effect of progress occurring exogenously over time [19]. For example, [21] argues that there is a constant rate of exogenous technological change associated with time. In highest cost category (CV), for example, compounded technological advancement of $0.50 \%$ per year until 2030 reduces the upper bound from 35.00 to 31.50 USD/BOE. Annual productivity gains in the upstream oil and gas sectors have historically been observed at an average of about 1\% [4]. However, periods of two-digit growth (usually in the short run) have often been followed by zero or negative increases, making productivity estimates highly uncertain [22]. Thus, our projected rates may prove to be pessimistic or optimistic. As stated in [16, p. 81], "the most important variable in the long run is the least predictable: technical progress both in supply and in utilization."

\footnotetext{
${ }^{3}$ Studies show that low initial learning rates in the early phases of commercial deployment (e.g. deep offshore production) results in increased costs [19]. On the other hand, greater experience - such as that occurring in categories CI and CII - leads to lower costs and faster improvements in technology. For the latter, [20] uses the example of power plants with $\mathrm{CO} 2$ capture.
} 
2 Table 2 presents 2009 and 2030 production costs in USD per MCF, as well as technological

3 improvement rates, for conventional gas. In this case, technological advancement is assumed to

4 range from $1.00 \%$ to $1.50 \%$ per year. The upper bound of the fifth cost category, $\mathrm{CV}$, has

5 decreased from 3.75 USD/MCF in 2009 to $3.00 \mathrm{USD} / \mathrm{MCF}$ in 2030, assuming compounded

6 technological change of $1.00 \%$ per year. It is important to note that the assumed rates of

7 technological progress will not occur automatically over time. Rather, significant investments will

8 be necessary to allow for productivity gains. Reduced interest rates should lead to increased

9 investment in oil and gas projects; particularly those with a high proportion of capital costs.

10 Considering our time horizon (to 2030), the eventual result would be increased production and

11 cost reductions due to technological learning. Conversely, an increase in interest rates will

12 discourage investment, leading to reduced future supply and augmented prices and costs. For a

13 detailed analysis on the relationship between interest rates and supply curves, refer to [23].

14

15

16

17

18

19

20

21

22

23

Table 1

Conventional oil production costs for 2009 and 2030 in USD/BOE

\begin{tabular}{|c|c|c|c|c|c|}
\hline \multirow{3}{*}{$\begin{array}{c}\text { Cost } \\
\text { Category }\end{array}$} & \multicolumn{2}{|c|}{ Production costs $(2009)^{a}$} & \multirow{3}{*}{$\begin{array}{c}\text { Technology } \\
\text { change } \\
\text { in } \% / y r \\
\end{array}$} & \multicolumn{2}{|c|}{ Production costs $(2030)^{c}$} \\
\hline & Lower Bound & Upper Bound & & Lower Bound & Upper Bound \\
\hline & (USD/BOE) & (USD/BOE) & & (USD/BOE) & (USD/BOE) \\
\hline \multicolumn{6}{|c|}{ Oil and NGL } \\
\hline CI & 3.00 & 7.00 & $1.50 \%$ & 2.20 & 5.10 \\
\hline CII & 7.00 & 13.00 & $1.50 \%$ & 5.10 & 9.45 \\
\hline CIII & 13.00 & 20.00 & $1.00 \%$ & 10.55 & 16.20 \\
\hline CIV & 20.00 & 29.00 & $0.50 \%$ & 18.00 & 26.10 \\
\hline $\mathrm{CV}$ & 29.00 & 35.00 & $0.50 \%$ & 26.10 & 31.50 \\
\hline
\end{tabular}

a. 2009 production costs based on [15].

b. Technology change rates assumed in this study, based on [4].

c. 2030 production costs estimated in this study. 
Table 2

Conventional gas production costs for 2009 and 2030 in USD/MCF

\begin{tabular}{|c|c|c|c|c|c|}
\hline \multirow[b]{2}{*}{ Cost } & \multicolumn{2}{|c|}{ Production costs $(2009)^{\mathrm{a}}$} & \multirow{3}{*}{$\begin{array}{c}\text { Technology } \\
\text { change } \\
\text { in } \% / y r\end{array}$} & \multicolumn{2}{|c|}{ Production costs $(2030)^{\mathrm{c}}$} \\
\hline & Lower Bound & Upper Bound & & Lower Bound & Upper Bound \\
\hline Category & (USD/MCF) & (USD/MCF) & & (USD/MCF) & (USD/MCF) \\
\hline \multicolumn{6}{|c|}{ Natural Gas } \\
\hline CI & 0.50 & 0.90 & $1.50 \%$ & 0.35 & 0.65 \\
\hline CII & 0.90 & 1.40 & $1.50 \%$ & 0.65 & 1.00 \\
\hline CIII & 1.40 & 2.30 & $1.50 \%$ & 1.00 & 1.65 \\
\hline CIV & 2.30 & 3.10 & $1.00 \%$ & 1.85 & 2.50 \\
\hline CV & 3.10 & 3.75 & $1.00 \%$ & 2.50 & 3.00 \\
\hline
\end{tabular}

a. 2009 production costs based on [15].

b. Technology change rates assumed in this study, based on [4].

c. 2030 production costs estimated in this study.

Applying the cost ranges of the five categories to the oil and gas volumes in a fixed proportion leads to estimated oil and gas supply cost curves for Europe. Based on [15], the proportion of oil across categories is assumed to be $5 \%(\mathrm{CI}), 15 \%(\mathrm{CII}), 60 \%(\mathrm{CIII}), 17.5 \%(\mathrm{CIV}), 2.5 \%(\mathrm{CV})$; for gas it is $30 \%(\mathrm{CI}), 47.5 \%(\mathrm{CII}), 15 \%$ (CIII), $5 \%$ (CIV), $2.5 \%(\mathrm{CV})$.

Figure 4 shows two oil supply curves - one for the volumes based on performance, productivity and costs associated with 2009 technology and one for the volumes, performance and production technology expected by 2030 . The 2030 curves reflect production cost reductions due to technological advances over the period. However, the volumes in 2030 exclude any potential enhancement to the accessible oil resource base made possible by technological change and different market conditions but reflect the oil produced between 2009 and 2030 (assuming constant 2009 production levels). In any case, the estimated volume for 2009 already includes the oil from previously unassessed provinces as well as reserve growth. Figure 5 follows the same procedure but presents supply curves for conventional gas. 
1 The potential oil volume assessed for 2009 amounts to some $151 \mathrm{BBOE}$. This is calculated by

2 subtracting European cumulative oil production until 2009, 57 BBOE [24], from the VSD-

3 calculated endowment plus reserve growth (208 BBOE). As defined above, endowment includes

4 cumulative production, so cumulative oil production must be subtracted from the endowment in

5 order to give the remaining volume. Assuming a constant oil production rate of $1.7 \mathrm{BBOE}$ per

6 year from 2009 to 2030 [24], the remaining total decreases to 114 BBOE in 2030.

7

8 For the case of gas, the total remaining volume in 2009 amounts to $1878 \mathrm{TCF}$. This is equal to the

9 VSD-calculated total of 2188 TCF minus cumulative gas production until 2009 (310 TCF). A

10 constant production rate of 9.8 TCF per year [24] is used to derive the volume in the 2030 supply

11 curve, 1662 TCF.

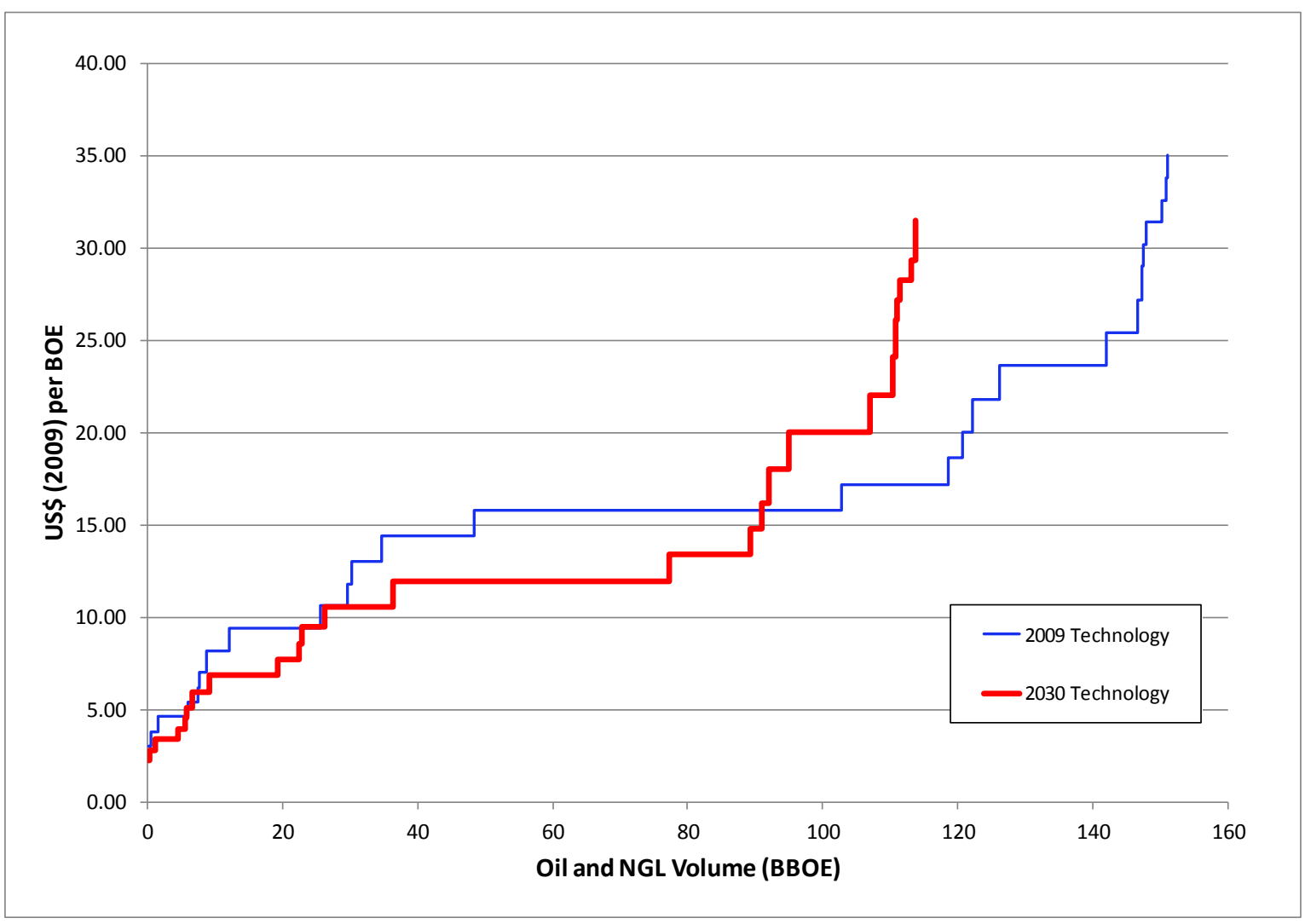

13 Fig. 4. 2009 and 2030 supply cost curves for conventional oil and NGL in Europe. 


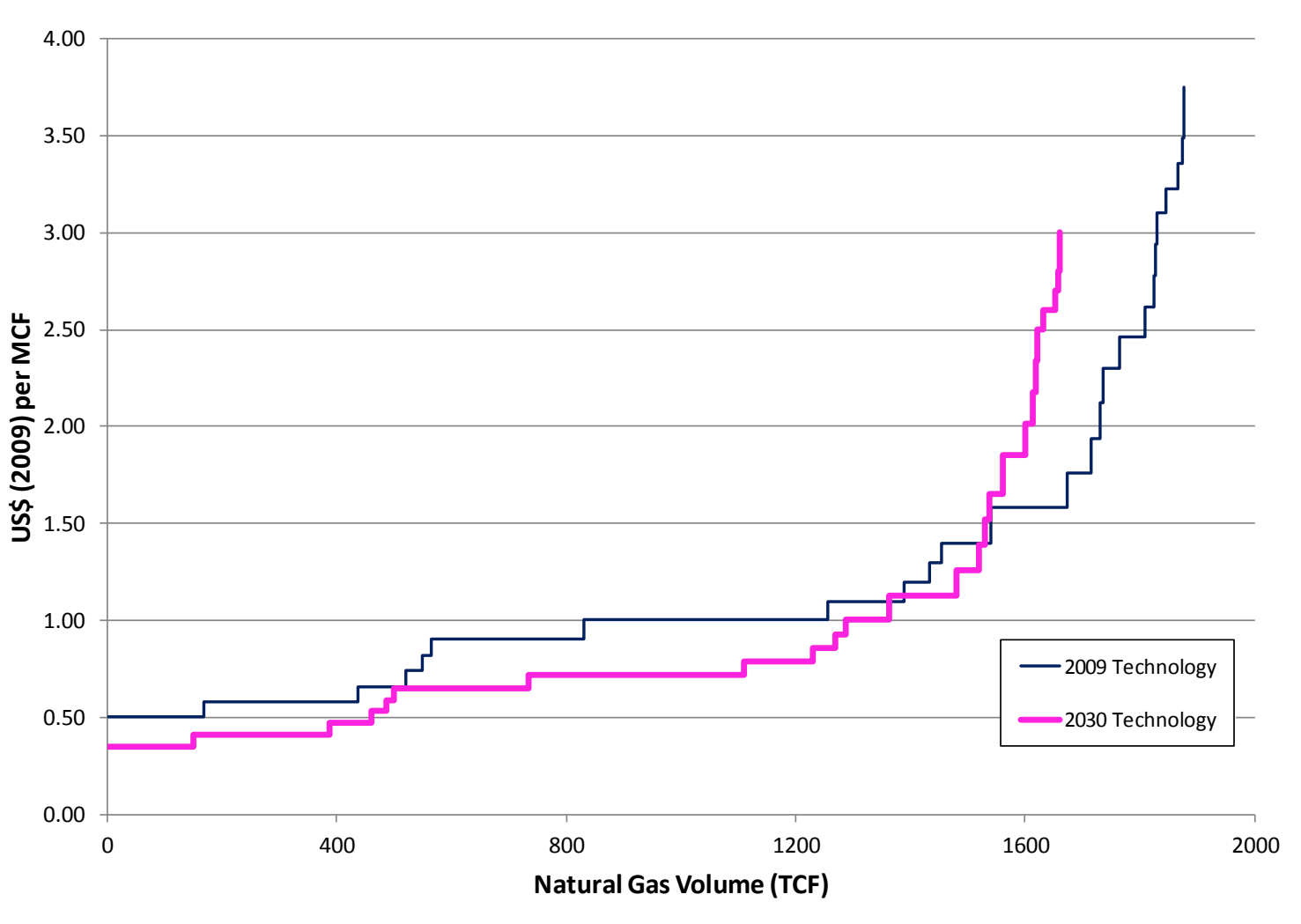

2 Fig. 5. 2009 and 2030 supply cost curves for conventional gas in Europe.

\section{Conclusions}

This study assesses the availability of conventional oil and gas in Europe by estimating supply cost curves. The curves are intended to show how the long term supply of oil or gas to the year 2030 varies with costs of production.

7

To begin with, we find that conventional oil and gas resources may be more abundant than many commentators assume. This is due to the significant yet-to-be-found volumes estimated to exist in

10 previously unassessed provinces, as well as the additions that could occur as a result of reserve

11 growth. The USGS (2000) study itself recognizes that their "assessment is not exhaustive,

12 because it does not cover all sedimentary basins ...The estimates are therefore conservative" [25]. 
Our VSD-calculated oil endowment volume, plus reserve growth, for all 62 provinces in Europe amounts to $208 \mathrm{BBOE}$, while the gas endowment including reserve growth is estimated at 2188 TCF. Another finding is that the oil and gas volumes are likely to be economic. This is deduced from the supply cost curves estimated in the previous section. The curves are constructed by attaching technological advancement over time, the production costs may decrease further. The projected year. For natural gas, the productivity gains vary between $1.0 \%$ and $1.5 \%$ per year. Although the rates are speculative, they approximate the average long-term historically observed rates in the hydrocarbon upstream sectors. In 2009, estimated production costs for oil ranged from 3.00 to 35.00 USD/BOE, while gas costs ranged from 0.50 to 3.75 USD/MCF. By 2030, the projected

14 oil production costs range from 2.20 to $31.50 \mathrm{USD} / \mathrm{BOE}$, while those for gas range from 0.35 to 3.00 USD/MCF.

\section{References}

[1] International Energy Agency, 2011. World Energy Outlook. Paris, France: Organization for Economic Cooperation and Development.

[2] United States Energy Information Administration , 2011. Independent Statistics \& Analysis, Washington DC: Department of Energy. [3] Wonglimpiyarat, J., 2010. "Technological Change of the Energy Innovation System: From Oil-based to Bio-based Energy", Applied Energy 87 (3): 749-755. 
[4] Rogner, H. H., 1998. “An Assessment of World Hydrocarbon Resources.” International Institute for Applied Systems Analysis (IIASA) Publications, RR-98-6. Also, Annual Review of Energy and Environment 1997. 22: 217-262.

[5] Aguilera, R.F., 2010. "The Future of the European Natural Gas Market: A Quantitative Assessment”, Energy 35 (8): 3332-3339.

[6] Tilton, J.E., 2002. On Borrowed Time? Assessing the Threat of Mineral Depletion. Washington, DC: Resources for the Future.

[7] Tilton, J.E. and Skinner, B.J., 1987. "The Meaning of Resources." In D.J. McLaren and B.J. Skinner, eds., Resources and World Development. New York: John Wiley \& Sons.

[8] Aguilera, R.F., 2006. "Assessing the Long Run Availability of Global Fossil Energy Resources", PhD Dissertation, Colorado School of Mines, Golden, Colorado, USA.

[9] United States Geological Survey, 2000. World Petroleum Assessment, CD-ROM.

[10] Barton C.C., 1995. A New Approach to Estimating Hydrocarbon Resources. United States Geological Survey Fact Sheet.

http://webharvest.gov/peth04/20041016205020/http://energy.usgs.gov/factsheets/HydroRes/estimat.html (accessed 23 December 2011).

[11] Kaufman G.M., 2005. "Where have we been? Where are we going?", Natural Resources Research 14 (3): 145-152.

[12] Drew L.J., 1997. Undiscovered Petroleum and Mineral Resources, Assessment and Controversy. New York and London: Plenum Press.

[13] Tangen, G. and Mølnvik, M.J., 2009. "Scenarios for Remote Gas Production”, Applied Energy 86 (12): 2681-2689.

[14] Verma, M.K., 2000. "The Significance of Field Growth and the Role of Enhanced Oil Recovery.” USGS Fact Sheet FS-115-00.

[15] Aguilera, R.F., Eggert, R.G., Lagos, G., Tilton, J.E., 2009. "Depletion and the Future Availability of Petroleum Resources”, Energy Journal 30 (1): 141-174.

[16] Adelman, M.A., 1993. The Economics of Petroleum Supply. Cambridge, Massachusetts: The MIT Press.

[17] SPE/WPC/AAPG/SPEE, 2007. Petroleum Resources Management System (PRMS). Society of Petroleum Engineers/World Petroleum Council/American Association of Petroleum Geologists/Society of Petroleum Evaluation Engineers. 
[18] UNFC, 2009. United Nations Framework Classification for Fossil Energy and Mineral Reserves and Resources. UN Economic Commission for Europe, Geneva.

[19] Yeh, S. and Rubin E.S., 2011. "A Review of Uncertainties in Technology Experience Curves", Energy Economics, in press.

[20] Rubin, E.S., Yeh, S., Antes, M.K., and Berkenpas, M.B., 2007. 'Use of Experience Curves to Estimate the Future Cost of Power Plants with CO2 Capture", International Journal of Greenhouse Gas Control 1: 188-197.

[21] Nordhaus, W., 2009. "The Perils of the Learning Model for Modeling Endogenous Technological Change", National Bureau of Economic Research (NBER) Working Paper Series No. 14638.

[22] Adelman, M.A., 1995. The Genie out of the Bottle: World Oil since 1970. Cambridge, Massachusetts: The MIT Press.

[23] Bauer, N., Edenhofer, O., Kypreos, S., 2008. "Linking Energy System and Macroeconomic Growth Models", Computational Management Science 5(1-2): 95-117.

[24] British Petroleum, 2010. Statistical Review of World Energy 2010, London: British Petroleum.

[25] Ahlbrandt, T.S. and McCabe P.J., 2002. "Global Petroleum Resources: A View to the Future." Geotimes 47 (11): 14-18.

http://www.agiweb.org/geotimes/nov02/feature_oil.html (accessed December 19, 2012). 